\title{
An Analysis Of The Day-Of-The-Week Effect In The Russian Stock Market
}

Carl B. McGowan, Jr., Norfolk State University, USA

Izani Ibrihim, Universiti Kebangsaan, Malaysia

\begin{abstract}
In this paper, we evaluate the weak form efficiency of the Russian Stock market using the Russian trading System Index for the period when the market opened in 1995 to August 2003 by testing for a day-of-the-week effect using ARCH/GARCH analysis. There does appear to have been a speculative bubble in the run-up to the market peak in late 1997 to early 1998 that burst when the government defaulted on debt. However, based on the empirical results of this paper, it appears that the RTSI does have a day-of-the-week effect. However, returns are lowest on Wednesday and highest on Friday and returns are positive on every day except Wednesday. Thus, we posit a three day "weekend" effect from Thursday to Monday.
\end{abstract}

\section{INTRODUCTION}

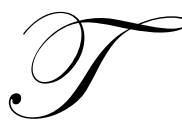

he day-of-the-week effect in the United States' stock market has been studied since Cross (1973) first reported a difference in returns for Friday and Monday. The effect was further identified in French (1980) who reports that returns are highest on Friday and lowest on Monday. Various explanations for the day-of-the-week effect in the US stock market are posited, such as settlement differences in Gibbons and Hess (1981) and Lakonishok and Levi (1982), measurement error in Keim and Stambaugh (1984), and a non-trading effect in Rogalski (1984). Although Berument and Kiymaz (2001) report that the day-of-the-week effect appears to continue to exist in the US stock market for the period from Janauary 1973 to October 1997, Gregoriou and Tsitianis (2002) report that once the bid-ask spread effect is included in the analysis, the day-of-theweek effect disappears for the UK stock market for the period from 1986 to December 1997.

Day-of-the-week effects are present in other developed stock markets. Jaffe and Westerfield (1985) find a day-of-the-week effect in stock markets in Australia, Canada, Japan, and the UK but the high/low days are not always Friday/Monday. However, Gregoriou and Tsitianis (2002) report that once the bid-ask spread effect is included in the analysis, the day-of-the-week effect disappears for the UK stock market.

Day-of-the-week effects are found in emerging markets. McGowan, Yener, and Johnson (1989) find a dayof-the-week effect for the Manila Mining Index for the period November 1976 to May 1987. Other emerging markets exhibit a day-of-the-week effect. Mookerjee and Yu (1999) find that the highest daily return occurs on Thursday, daily price limits affect price changes, and daily stock returns are positively correlated in the Shanghai and Shenzhen Securities Exchanges. Al-Loughani and Chappell $(2001)$ use a non-linear GARCH $(1,1)$ model to explain day-of-the week effect of the Kuwait stock exchange index and allows identification and modeling of the day-of-the-week effect. Poshakwale and Murinde (2001) use daily indexes of the Hungarian and Polish stock exchanges to develop a GARCH-H model and reject the martingale hypothesis but do not find the Friday-Monday day of the week effect. Mille, Markellos, and Harizanis (2000) analyze calendar effects for each stock in the Athens Stock Exchange General Index for the Period October 1986 to April 1997 and find day-of-the-week effects. Curci and Brown (2001) find a day-of-the-week effect for five Medellin Stock Exchange price indexes.

The use of ARCH/GARCH models is prevalent in the analysis of day-of-the-week effects for controlling both differences in mean returns and differences in volatility. Apergis and Eleptheriou (2001) analyze the behavior of volatility of daily returns for the Athens Stock Exchange for 1990-1999 using a GQARCH(1,2) model and find that the persistence in volatility clustering implies inefficiency. Kamath and Chusanachoti (2000) use daily return 
and volume data for two emerging markets, Korea and Thailand, in a GARCH model and find that volume does not affect the ARCH or GARCH process. Adrangi, Raffiee and Shank (1999) examine volatility persistence in returns in stock markets in Greece, Portugal, and Spain using a TARCH model with moving averages to account for asymmetric effects. All three markets exhibit volatility persistence.

Over the period of time that the day-of-the-week effect has been studied beginning with Cross (1973), the day-of-the-week effect persists both in large, well-developed stock markets, such as the US, Japanese, and the UK stock markets and in smaller, developed markets such Australia, and Canada. The day-of-the-week effect exists in emerging markets in countries such as Hungary, Poland, Greece, and China. The ARCH/GARCH paradigm developed from Engle (1982) and Bollerslev (1986) provides a basis for analyzing the time varying mean and variance effects of the day-of-the-week effect.

\section{Testing the Day-of-the-Week Effect}

We test for the day-of-the-week effect in the Russian Trading System Index using daily returns taken from the RTS website for the period from the opening of the RTS in September 8, 1995 to August 11, 2003. Daily index values, $\mathrm{I}_{\mathrm{t}}$, are used to compute daily returns, $\mathrm{R}_{\mathrm{t}}$.

$\mathrm{R}_{\mathrm{t}}=\ln \left(\mathrm{I}_{\mathrm{t}} / \mathrm{I}_{\mathrm{t}-1}\right)$

where, in is the natural logarithm operator. Daily returns computed this way are the continuously, compounded, percentage returns from day to day.

Initially, we use dummy variable regression to determine the day-of-the-week effect in the RTS. A linear regression is run where each day is represented by a dummy variable equal to one if the return is for the day and equal to zero if the return is for another day.

$R_{d}=D_{M} R_{M}+D_{T} R_{T}+D_{W} R_{W}+D_{R} R_{R}+D_{F} R_{F}+\varepsilon_{t}$

where, the D's represent the dummy variables for each day, Monday, Tuesday, Wednesday, Thursday, and Friday and the R's represent the return for each day. This model assumes that the error terms and variances are constant across time. In addition, Wooldridge (2003) shows that multiple linear regression assumes that the parameters are linear, the sample is random, the error terms are mean zero, none of the variables are perfectly collinear, and the regression coefficients are unbiased. However, if these assumptions are not met, the empirical results will not yield parameter estimates that are the best, linear, unbiased, estimators.

The auto-regressive, conditional heteroskedastic model was developed in Engle (1982) and generalized in Bollserlev (1986). The GARCH $(1,1)$ model used in this paper is described by the following system of equations:

$\mathrm{R}_{\mathrm{t}}=\alpha_{0}+\beta_{1} \mathrm{R}_{\mathrm{t}-1}+\varepsilon_{\mathrm{t}}$

where, $R_{t}$ are the stochastic stock market returns, $\beta_{1}$ is the regression parameter, $R_{t-1}$ is the series of lagged explanatory variables, and $\varepsilon_{\mathrm{t}}$ is the vector of error terms. The return generating process is auto-regressive. The error term, $\varepsilon_{\mathrm{t}}$, is determined by a vector of lagged, error terms, $\varepsilon_{\mathrm{t}}=\mathrm{f}\left(\varepsilon_{\mathrm{t}-1}, \varepsilon_{\mathrm{t}-2}, \varepsilon_{\mathrm{t}-3}, \ldots\right)$, and is distributed normally with mean zero and variance equal to $h_{t}$. The variance of $\varepsilon_{t}$ is equal to the squared value of the lagged error term and the lagged value of the variance.

$\mathrm{h}_{\mathrm{t}}=\mu+\alpha_{1} \varepsilon_{\mathrm{t}-1}^{2}+\alpha_{2} \mathrm{~h}_{\mathrm{t}-1}$

The $\varepsilon_{\mathrm{t}-1}^{2}$ term is determined by the volatility of the lagged error and the $\mathrm{h}_{\mathrm{t}-1}$ term is determined by the forecast error of the previous period, $\left(\mathrm{h}_{\mathrm{t}-1}-\mathrm{h}_{\mathrm{t}-2}\right)$. Equation (3) is the equation of the mean conditional on the past returns as an auto-regressive process. Equation (4) is the variance equation determined by the lagged values of the squared, lagged error terms, $\varepsilon_{t-1}^{2}$, and the lagged error terms, $\left(\mathrm{h}_{\mathrm{t}-1}-\mathrm{h}_{\mathrm{t}-2}\right)$. If the sum of the two regression coefficients in Equation (2) is equal to one, the volatility shocks are persistent. 
The model that we test combines Equation (2) and Equation (4):

$R_{d}=D_{M} R_{M}+D_{T} R_{T}+D_{W} R_{W}+D_{R} R_{R}+D_{F} R_{F}+\alpha_{1} \varepsilon_{t-1}^{2}+\alpha_{2} h_{t-1}$

Equation (5) contains the five dummy variables representing the day-of-the-week and the lagged error terms and the lagged error terms.

\section{The Russian Trading System (http://www.rts.ru)}

The RTS opened in September 1, 1995 and currently lists over 400 securities including common stock, preferred stock and bonds (50). The RTS Index is the official indicator of the RTS and is reported to financial information services every 30 minutes from real-time prices of the 50 most liquid stocks listed on the RTS. There are three levels of stocks on the RTS, for reporting purposes, assigned by the Information Committee at intervals of three months or longer. Stocks are assigned to levels based on total market capitalization, average daily traded volume, frequency of trading, the existence of demands and offers, the size of the spread, and any other factors deemed to be important by the Information Committee. Level 1 contains seven stocks, Level 2 contains 24 stocks, and Level 3 contains the remaining stocks. Changes in the securities in each level are implemented with a onemonth delay.

The RTSI is computed and reported every 30 minutes from the opening price at 12:00 to 17:30 with the closing level computed at 18:10. The RTSI is computed in dollars, converted to rubles, and both values are reported. The ending value for the index, $\mathrm{I}_{\mathrm{t}}$, is the beginning value of the index, $\mathrm{I}_{\mathrm{t}-\mathrm{1}}$, multiplied by the ratio of the ending market capitalization of the stocks in the index, $\mathrm{MC}_{\mathrm{t}}$, divided by the beginning value of the market capitalization of the stocks in the index, $\mathrm{MC}_{\mathrm{t}-1}$. The market capitalization is calculated as the total number of shares outstanding times the stock price for each security in the RTSI calculated in dollars. The ruble value of the index is the ratio of the ending value of the ruble exchange rate divided by the beginning value of the ruble dollar exchange rate. The initial value of the RTSI on September 1, 1995 was 100 and the ruble to dollar exchange rate was 4.447 rubles per US dollar.

\section{Empirical Results}

Table 1 contains the summary statistics for the total sample for the RTSI and for each day of trading. For the total sample, there are 1976 observations with a mean value of 0.0008 and with a standard deviation of 0.0315 . The maximum value is 0.1556 and the minimum value is -0.2110 . The skewness is 0.3287 and the Kurtosis is 4.73 . For the daily observations, the highest mean return is for Friday, 0.0025, and the lowest mean return is for Wednesday, -0.0028 . The standard deviation is highest for Wednesday, 0.0303, and lowest for Friday, 0.0281. The Jarque-Bera statistics indicate that the daily returns distributions are not normally distributed. The returns are skewed positively except Friday and leptokurtic.

Table 1

Russian Trading System Index Daily Rates of Return Summary Statistics

\begin{tabular}{|l|c|c|c|c|c|c|}
\hline \multicolumn{1}{|c|}{ Statistics } & Total Sample & Monday & Tuesday & Wednesday & Thursday & Friday \\
\hline Number & 1976 & 385 & 406 & 399 & 399 & 387 \\
\hline Mean & 0.0008 & 0.0018 & 0.0013 & -0.0028 & 0.0010 & 0.0025 \\
\hline Median & 0.0011 & 0.0027 & 0.0006 & -0.2218 & 0.0033 & 0.0015 \\
\hline Maximum & -0.2110 & 0.1471 & 0.1555 & 0.1454 & 0.1238 & 0.1556 \\
\hline Minimum & 0.1556 & -0.1549 & -0.2110 & -0.1766 & -0.1878 & -0.1093 \\
\hline Std Dev & 0.0315 & 0.0328 & 0.0303 & 0.0337 & 0.0321 & 0.0281 \\
\hline Skewness & 0.3287 & -0.3136 & -0.2596 & -0.4425 & -0.6735 & 0.4033 \\
\hline Kurtosis & 4.73 & 6.94 & 11.11 & 6.69 & 7.05 & 6.59 \\
\hline
\end{tabular}


Table 2 contains the regression results for the OLS using dummy variables only. None of the regression coefficients are statistically significant at the five percent level but the regression coefficient for the Wednesday dummy variable is statistically significant at the eight percent level. These results would indicate that the differences in the daily returns of the five different days of the week are not statistically significant in explaining returns. However, given the non-normality of the returns distributions, these results may be suspect. Thus, we use ARCH/GARCH analysis.

Table 2

Russian Trading System Index

Method: Least Squares

Sample(adjusted): 9/04/1995 3/31/2003

Included observations: 1976 after adjusting endpoints

\begin{tabular}{|l|c|c|c|c|}
\hline \multicolumn{1}{|c|}{ Variable } & Coefficient & Standard Error & T-Statistic & Probability \\
\hline D1 & 0.001849 & 0.001604 & 1.1523 & 0.2493 \\
D2 & 0.001310 & 0.001562 & 0.8385 & 0.4018 \\
D3 & -0.002759 & 0.001576 & -1.7504 & 0.0802 \\
D4 & 0.001047 & 0.001576 & 0.6646 & 0.5064 \\
D5 & 0.002513 & 0.001600 & 1.5702 & 0.1165 \\
\hline \multicolumn{5}{|l|}{} \\
\hline R-squared & 0.0034 & Mean dependent variable & 0.0008 \\
Adjusted R-squared & 0.0014 & S.D. dependent variable & 0.0315 \\
S.E. of regression & 0.0315 & Akaike information criterion & -4.0763 \\
Sum squared residual & 1.9533 & Schwarz criterion & -4.0622 \\
Log likelihood & 4032 & Durbin-Watson stat & 1.6722 \\
\hline
\end{tabular}

Table 3 contains the regression results for the maximum likelihood GARCH analysis. The sum of the $\mathrm{ARCH}$ and GARCH regression coefficients is 0.984 , which indicates that the volatility is persistent. The regression coefficients for the dummy variables representing Monday, Thursday, and Friday are statistically significant at the five percent level. The ARCH variable is positive and statistically significant with a Z-statistic of 15 . This means that the returns on a particular day are influenced by the returns on the previous day. High returns for a day indicate high returns for the following day. The GARCH term is positive and statistically significant with a Z-statistic of 56. This indicates that if the error is positive on a particular day, the error on the following day will be positive. The likelihood ratio is 4342 which indicates that these results are statistically significant.

Table 3

Russian Trading System Index

GARCH(1,1) Regression Results

Method: ML - ARCH

Sample(adjusted): 9/04/1995 8/11/2003

Included observations: 1976 after adjusting endpoints

\begin{tabular}{|l|c|c|c|c|}
\hline \multicolumn{1}{|c|}{ Variable } & Coefficient & Standard Error & Z-Statistic & Probability \\
\hline D1 & 0.002636 & 0.001088 & 2.4239 & 0.0154 \\
D2 & 0.001164 & 0.001111 & 1.0477 & 0.2948 \\
D3 & -0.000922 & 0.000997 & -0.9248 & 0.3551 \\
D4 & 0.002465 & 0.001075 & 2.2940 & 0.0218 \\
D5 & 0.002246 & 0.001136 & 1.9767 & 0.0481 \\
\hline \multicolumn{5}{|c|}{ Variance Equation } \\
\hline C & 0.000005 & 6.8900 & 0.0000 \\
ARCH(1) & 0.014843 & 15.3902 & 0.0000 \\
GARCH(1) & 0.000035 & 55.5922 & 0.0000 \\
\hline \multicolumn{5}{|c|}{} \\
\hline R-squared & 0.228440 & 0.013609 & 0.0008 \\
Adjusted R-squared & 0.756574 & Mean dependent variable & 0.0315 \\
S.E. of regression & 0.0022 & S.D. dependent variable & -4.3871 \\
Sum squared residual & -0.0013 & Akaike information criterion & -4.3644 \\
Log likelihood ratio & 0.0315 & Schwarz criterion & 1.6719 \\
\hline
\end{tabular}




\section{SUMMARY AND CONCLUSIONS}

In this paper, we find that the lowest returns are for Wednesday and are negative but not statistically significant and that highest returns are for Friday and are positive but not statistically significant. Returns for Monday, Tuesday, and Thursday are all similar, approximately 0.001 , but not statistically significant.

However, using standard ARCH/GARCH analysis to determine if a day-of-the-week effect exists in the RTS Index, we find that a day-of-the-week effect exists but is not consistent with the US stock market Monday/Friday ("weekend"), day-of-the-week effect. Wednesday provides the lowest rate of return and Thursday, Friday, and Monday provide positive returns that are statistically significant. These results indicate that there is a momentum effect for a three day "weekend" for the RTSI and that returns for these three days are persistent. Given the significant gyrations of the RTSI from the early run-up of the index from inception to the beginning of the crash in August 1998 and given that the RTSI is an emerging market, the RTSI market return distributions are more consistent that one might expect. However, there is persistence in the form of a three day "weekend" effect.

Russia is important in the world economy for several reasons. Russia is large, has a large population, is raw materials rich, and has a significant military presence. Thus, it is important that the Russian economy grow and develop in order to provide a higher standard of living for the Russian citizens. An integral part of economic growth and development is an efficient stock market to provide the needed resources to entrepreneurs, McGowan (2008). The results of this study indicate that the RTSI is not sufficiently efficient and further stock market development is necessary.

\section{REFERENCES}

1. Adrangi, Bahram, Kambiz Raffiee, and Todd Shank. "European Emerging Markets and the World Market Volatility," Global Business and Finance Review, volume4, number 1, Spring 1999.

2. Al-Loughani, Nabeel and David Chappell. "Modeling the Day-of-the-week Effect in the Kuwait Stock Exchange: A Non-linear GARCH Representation,” Applied Financial Economics, volume 11, number 4, August 1, 2001, pp. 353-359.

3. Apergis, Nicholas and Sophia Eleptheriou. "Stock returns and Volatility: Evidence from the Athens Stock Market Index.” Journal of Economics and Finance, volume 25, number 1, Spring 2001, pp. 50-61.

4. Berumet, Hakan and Halil Kiymaz. "The Day of the Week Effect on Stock Market Volatiliyt," Journal of Economics and Finance, volume 25, number 2, Summer 2001, pp. 181-193.

5. Bollerslev, T. "Generalized Autoregressive Conditional Heteroskedasticity," Journal of Econometrics, volume 31, pp. 307-327.

6. Cross, R. A. "The Behavior of Stock Market Prices on Mondays and Fridays," Financial Analysts Journal, November-December 1973, pp. 67-69.

7. Curci, Roberto and Cynthia J. Brown. "Pattern of Equity Returns in Emerging Markets: The Case of Colombia," Global Business and Finance Review, volume 6, number 1, Spring 2001.

8. Engle, Robert F. "Autoregressive Conditional Heteroskedasticity with Estimates of the Variance of UK Inflation," Econometrica, volume 50, pp. 987-1007.

9. French, Kenneth R. "Stock Returns and the Weekend Effect," Journal of Financial Economics," volume 8, 1980, pp. 55-69.

10. Gibbons, M. R. and P. Hess. "Day of the Week Effects," Journal of Business, volume 54, 1981, pp. 579596.

11. Gregoriou, A., A. Kontonikas, and N. Tsitsianis. "Does the Day-of-the-Week Effect Exist once Transactions Costs Are Accounts For? Evidence from the UK," Working Paper, Brunel University, February 2002.

12. Jaffe, J. and R. Westerfield. "The Weekend Effect in Common Stock Returns: The International Evidence," Journal of Finance, volume 40, pp. 433-454.

13. Kamath, Ravindra and Jirayuth Chusanachoti. "The Dependence of Market Return Volatility on Trading Volume in Korea and Thailand," Global Business and Finance Review, volume 5, number 1, Spring 2000.

14. Keim, D. B. and R. F. Stambaugh. "A Further Investigation of the Weekend Effect in Stock Returns," Journal of Finance, volume 39, 1984, pp. 819-835. 
15. Lakonishok, J. and S. Schmidt. “Are Seasonal Anomalies Real? A 90 Year Perspective,” Review of Financial Studies, volume 1, 1988, pp. 403-425.

16. McGowan, Carl B., Jr. "A Study of the Relationship between Stock Market Development and Economic Growth and Development from 1994 to 2003," International Business and Economics Research Journal, May 2008, Volume 7, Number 5, pp. 79-86.

17. McGowan, Carl B., Jr., Demir Yener, and James Johnson. "Seasonal Effects in the Philippine Stock Market: Evidence of Daily and Monthly Pricing Anomalies," Advances in Business Studies, volume 2, number 1, 1989, pp. 59-68.

18. Mille, T. C., C, Siriopoulos, R. N. Markellos, and D. Harizanis. "Seasonality in the Athens Stock Exchange," Applied Financial Economic volume 10, number 2, April 1, 2000, pp. 137-142.

19. Mookerjee, Rajen and Qiao Yu. "Seasonality in Returns on the Chinese Stock Markets: The Case of Shanghai and Shenzhen," Global Finance Journal, volume 10, Number 1, 1999.

20. Poshakwale, Sunil and Victor Murinde. "Modeling the Volatility in East European Emerging Markets: Evidence on Hungary and Poland," Applied Financial Economic volume 11, number 4, August 1, 2001, pp.45-456.

21. Rogalski, Richard J. "New Findings Regarding Day-of-the-Week Returns over Trading and Non-Trading Periods: A Note," Journal of Finance, volume 39, number 5, December 1984, pp. 1603-1614.

22. Russian Stock Exchange web site, http://www.rts.ru.

23. Wooldridge, Jeffrey M. Introductory Econometrics: A Modern Approach, Thomson Southwestern, Mason, OH, 2003. 